\title{
Transcriptional Regulation of HMOX1 Gene in Hezuo Tibetan Pigs: Roles of WT1, Sp1, and C/EBP $\alpha$
}

\author{
Wei Wang ${ }^{1}$, Qiaoli Yang ${ }^{1}$, Kaihui Xie ${ }^{1}$, Pengfei Wang ${ }^{1}$, Ruirui Luo ${ }^{1}$, Zunqiang Yan ${ }^{1}{ }^{1}$, \\ Xiaoli Gao ${ }^{1}$, Bo Zhang ${ }^{1}$, Xiaoyu Huang ${ }^{1}$ and Shuangbao Gun ${ }^{1,2, *}$ \\ 1 College of Animal Science and Technology, Gansu Agricultural University, Lanzhou 730070, China; \\ wangw@st.gsau.edu.cn (W.W.); yangq10112@163.com (Q.Y.); xkh34567@163.com (K.X.); \\ wangpf815@163.com (P.W.); luoruirui628@163.com (R.L.); yanzunqiang@163.com (Z.Y.); \\ gx118892@163.com (X.G.); zhangb1662@163.com (B.Z.); huanghxy100@163.com (X.H.) \\ 2 Gansu Research Center for Swine Production Engineering and Technology, Lanzhou 730070, China \\ * Correspondence: gunsbao056@126.com; Tel.: +86-931-763-1804
}

Received: 3 March 2020; Accepted: 24 March 2020; Published: 26 March 2020

\begin{abstract}
Heme oxygenase 1 (HMOX1) is a stress-inducing enzyme with multiple cardiovascular protective functions, especially in hypoxia stress. However, transcriptional regulation of swine HMOX1 gene remains unclear. In the present study, we first detected tissue expression profiles of HMOX1 gene in adult Hezuo Tibetan pig and analyzed the gene structure. We found that the expression level of HMOX1 gene was highest in the spleen of the Hezuo Tibetan pig, followed by liver, lung, and kidney. A series of 5' deletion promoter plasmids in pGL3-basic vector were used to identify the core promoter region and confirmed that the minimum core promoter region of swine HMOX1 gene was located at $-387 \mathrm{bp}$ to $-158 \mathrm{bp}$ region. Then we used bioinformatics analysis to predict transcription factors in this region. Combined with site-directed mutagenesis and RNA interference assays, it was demonstrated that the three transcription factors WT1, Sp1 and C/EBP $\alpha$ were important transcription regulators of $H M O X 1$ gene. In summary, our study may lay the groundwork for further functional study of HMOX1 gene.
\end{abstract}

Keywords: HMOX1 gene; promoter; transcriptional regulation; Hezuo Tibetan pig

\section{Introduction}

Tibetan pigs are typical high-altitude pig breeds living on the Qinghai-Tibet Plateau, and are vital to the lives of Tibetan people [1]. The main producing areas of Hezuo Tibetan pigs are located in the southwestern of Gansu province in Gannan Tibetan Autonomous Prefecture, on the northeast edge of the Qinghai-Tibet Plateau, with an average elevation of about 3000 meters [2]. Hezuo Tibetan pigs belong to a group of Tibetan pigs, which can adapt to the harsh plateau environment and feeding conditions, mainly relying on grazing for their livelihood [3]. Genomic analyses found that there were different patterns of selection between domestic Duroc pigs and Titetan wild boars. Tibetan pigs have a higher proportion of lineage-specific genes, these specific genes were related to vascular smooth muscle contraction, disease resistance, and chemokine signaling pathway, which may reflect that Tibetan wild boar experienced natural selection to adapt to harsh environments [4]. Genome-wide SNP markers confirmed that the divergent evolution between Chinese and Western pigs, the interpopulation linkage disequilibrium, is much longer in Western pigs compared with Chinese pigs. In the genomic research to identify the candidate loci between Tibetan pigs and lowland pigs, several genes in Tibetan pigs are likely important for genetic adaptation to high altitude [5]. Previous research has shown that the adaptability of Tibetan pigs at high altitudes is significantly different from that of other domestic pigs. Tibetan pigs have evolved physiological characteristics to adapt to hypoxia in the plateau, 
such as a thicker alveolar septum, more developed capillaries [4], and larger and stronger hearts [5]. Therefore, an in-depth study of Tibetan pigs will help us understand the hypoxic adaptability of plateau species [6].

Heme oxygenase $(\mathrm{HO})$ is a stress-inducing enzyme that catalyzes heme to produce free iron, carbon monoxide (CO), and biliverdin [7]. Heme oxygenase 1 (HMOX1), one of the main members of the $\mathrm{HO}$ family, has a variety of cardiovascular protective functions [8-10] and plays an important role in anti-inflammatory, anti-apoptotic, and antioxidant activities among others [11-13]. HMOX1 exerts protective effects under stress conditions mainly through the active gas $\mathrm{CO}$ and antioxidant bilirubin produced by its decomposition [14,15]. In addition, as a protective gene, HMOX1 has been reported to have protective effects in acute and chronic lung injury such as hyperoxia, hypoxia, ischemia, and hypertension [16-19]. Although there have been many reports on the structure and function of HMOX1 gene, its transcriptional regulation mechanism has not been fully elucidated. Promoters play a major role in the regulation of gene transcription, and in-depth study of gene promoters is of great significance in explaining biological growth and development and disease defense [20].

Therefore, in the present study, with the Hezuo Tibetan pigs as the research object, we aim to explore the transcriptional regulation mechanism of the HMOX1 gene, and understand the promoter structure and transcriptional activity of Tibetan HMOX1 gene. First, the mRNA expression level of Hezuo Tibetan pig HMOX1 gene in different tissues was quantified. Then, we cloned 5' flanking promoter region and analyzed the sequence of HMOX1 gene. In addition, a series of deletion recombinant plasmids were constructed for double-luciferase activity analysis. The transcription factor binding sites of the core promoter region was predicted by bioinformatics software. To further investigate the regulatory mechanism of this gene, site-directed mutation and RNA interference experiments were used to verify the critical transcription factors that regulate the HMOX1 gene. This study will provide a reference for further studying the function of HMOX1 gene and lay a foundation for research transcriptional regulation mechanism of pig HMOX1 gene.

\section{Materials and Methods}

\subsection{Ethics Statement}

All animal experimental procedures used in this study were carried out following the guidelines of the China Council on Animal Care, and the protocols were subject to approval by the ethics committee of College of Animal Science and Technology, Gansu Agricultural University (approval number 2006-398).

\subsection{Quantitative Real-Time PCR Analysis of Gene Expression Patterns}

Fourteen tissues (heart, liver, spleen, lung, kidney, stomach, duodenum, jejunum, ileum, cecum, colon, rectum, psoas, dorsal longest muscle) were collected respectively from three adult Hezuo Tibetan pig in Hezuo, Tibetan Autonomous Prefecture of Gannan, China. Total RNA was extracted with TransZol Up reagent (TransGen Biotech, Beijing, China). For reverse transcriptional reaction, the first-strand cDNA was obtained according to the instructions of PrimeScript ${ }^{\mathrm{TM}} \mathrm{RT}$ reagent kit with gDNA Eraser (TaKaRa, Dalian, China). The qRT-PCR was analyzed using TB Green Premix Ex Taq II (Tli RNaseH Plus) quantitative kit (TaKaRa, Dalian, China) and each reaction mixture was incubated in the Roche LightCycler 480 II instrument (Roche Applied Science, Penzberg, Germany). The primer information in this experiment is shown in Table 1. Relative expression levels of all genes were normalized with of $\beta$-actin (ACTB) expression, and the $2^{-\Delta \Delta C t}$ method was used to calculate gene expressions [21].

\subsection{HMOX1 Gene Promoter Region Cloning and Bioinformatics Analysis}

The genomic DNA was extracted from Hezuo Tibetan pig blood using the TIANamp Blood DNA Kit (TIANGEN, Beijing, China), which as a template for PCR amplifications. An $\sim 2 \mathrm{~kb}$ promoter region of the 
Hezuo Tibetan pig HMOX1 gene (NCBI accession no. NM_001004027.1, region from 1952829 to 1954953) was amplified using specific primers (HMOX1-P-F/R, Table 1). Transcription initiation site (TSS) was predicted using Neural Network Promoter Prediction (http://www.fruitfly.org/seq_tools/promoter.html) online software, AliBaba2.1 [22] (http://gene-regulation.com/pub/programs/alibaba2/index.html) and JASPAR [23] (http://jaspar.genereg.net/) were used to predict the potential transcription factor binding sites. The CpG islands were predicted using MethPrimer [24] (http://www.urogene.org/methprimer/). NCBI Conserved Domain Database (CDD) (https://www.ncbi.nlm.nih.gov/cdd) was used to analyze the conserved domain. Nucleotide homology analysis was performed using the core promoter sequence of HMOX1 gene, mainly including six species: pig (Sus scrofa, NW_018084968.1), human (Homo sapiens, NC_000022.11), mouse (Mus musculus, NC_000074.6), cattle (Bos taurus, NC_037332.1), sheep (Ovis aries, NC_040254.1), and horse (Equus caballus, NC_009171.3). MEGA7.0 software was used for multi-sequence alignment and homologous tree construction.

Table 1. Primer information in this study

\begin{tabular}{|c|c|c|c|c|}
\hline Name & Primer Sequence $\left(5^{\prime}-3^{\prime}\right)$ & $\operatorname{Tm}\left({ }^{\circ} \mathrm{C}\right)$ & Length & Region \\
\hline HMOX1-P & $\begin{array}{l}\text { F: GCCTCGTCCTTCTAAAGTCCC } \\
\text { R: CGCCAAAGCCCAAGTGACTG }\end{array}$ & 56 & $2125 \mathrm{bp}$ & $\begin{array}{l}-1911 /-1892 \\
+214 /+195\end{array}$ \\
\hline HMOX1-RT & $\begin{array}{l}\text { F: GACATGGCCTTCTGGTATGGG } \\
\text { R: CATGTAGCGGGTGTAGGCGT }\end{array}$ & 60 & $141 \mathrm{bp}$ & $\begin{array}{l}348-368 \\
488-469\end{array}$ \\
\hline WT1-RT & $\begin{array}{l}\text { F: GGTGTCTTCAGGGGCATTCA } \\
\text { R: ACACATGAAGGGGCGTTTCT }\end{array}$ & 60 & $102 \mathrm{bp}$ & $\begin{array}{l}1127-1146 \\
1228-1209\end{array}$ \\
\hline Sp1-RT & $\begin{array}{l}\text { F: TGTCTCTGGTGGGCAGTATG } \\
\text { R: TTGCCCATCAACCGTCTGG }\end{array}$ & 60 & $133 \mathrm{bp}$ & $\begin{array}{l}601-620 \\
733-715\end{array}$ \\
\hline $\mathrm{C} / \mathrm{EBP} \alpha-\mathrm{RT}$ & $\begin{array}{l}\text { F: GGCAAAGCCAAGAAGTCGGT } \\
\text { R: TCTGTTGAGTCTCCACGTTGC }\end{array}$ & 60 & $124 \mathrm{bp}$ & $\begin{array}{c}976-995 \\
1099-1079\end{array}$ \\
\hline$\beta$-actin-RT & $\begin{array}{l}\text { F: ATATTGCTGCGCTCGTGGT } \\
\text { R: TAGGAGTCCTTCTGGCCCAT }\end{array}$ & 60 & $148 \mathrm{bp}$ & $\begin{array}{l}142-160 \\
289-270\end{array}$ \\
\hline HMOX1-P1 & F: CTAGCTAGCTATGACCGCTCCTCCTCCAC & 60 & $273 \mathrm{bp}$ & $-158 /+115$ \\
\hline HMOX1-P2 & F: CTAGCTAGCCAGGGTTTGGGGTGCAGAAG & 60 & $502 \mathrm{bp}$ & $-387 /+115$ \\
\hline HMOX1-P3 & 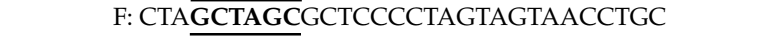 & 64 & $1034 \mathrm{bp}$ & $-919 /+115$ \\
\hline HMOX1-P4 & 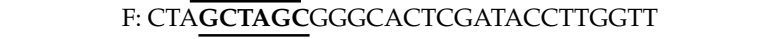 & 60 & $1732 \mathrm{bp}$ & $-1617 /+115$ \\
\hline HMOX1-P5 & F: CTA $\overline{\text { GCTAGCCAGCAACCCCCAAGTCTCT }}$ & 62 & $1993 \mathrm{bp}$ & $-1878 /+115$ \\
\hline HMOX1-R & R: CCGCTCGAGTTGCCTGTTGGGCTGTGAG & & & \\
\hline WT1-m & $\begin{array}{l}\text { F: GAAGTCCCTGAGGTCGCCGGTCCCTCCCGCTCAGAGAAGC } \\
\text { R: GCTTCTCTGAGCCAGCGGCCAGGGAGGGCTCAGGGACTTC }\end{array}$ & & $229 \mathrm{bp}$ & $-387 /-158$ \\
\hline Sp1-m & $\begin{array}{l}\text { F: GGCACCATTCAGATCCGT } \overline{\text { AAAA }} \text { GTGCTCAAGTCCCATCGC } \\
\text { R: GCGATGGGACTTAGGCA } \overline{\text { TTTTCACGAGCTGAATGGTGCC }}\end{array}$ & & $229 \mathrm{bp}$ & $-387 /-158$ \\
\hline $\mathrm{C} / \mathrm{EBP} \alpha-\mathrm{m}$ & $\begin{array}{l}\text { F: TCAGATTCCTAAAGTATC } \overline{\text { RAAAGGTTTGTTTTTAGTGTCC }} \\
\text { R: GGACACTAAAAATCATAGTTTTCGAAACTTAGGAATCTGA }\end{array}$ & & $229 \mathrm{bp}$ & $-387 /-158$ \\
\hline c-Ets-1-m & $\begin{array}{c}\text { F: CTTTTGCTTTGTTTTTAGACAGCTGTTTTAAACAGCTCTG } \\
\text { R: CAGAGCTGTTTAAAAATCTGTCGACAAAACAAAGVAAAAG }\end{array}$ & & $229 \mathrm{bp}$ & $-387 /-158$ \\
\hline si-WT1 & $\begin{array}{l}\text { F: GGGCUGCA } \overline{A U A A} G A G A U A U T T \\
\text { R: AUAUCUCUUAUUGCAGCCCTT }\end{array}$ & & & \\
\hline si-Sp1 & $\begin{array}{l}\text { F: GCGGAUCUGCAGUCCAUUATT } \\
\text { R: UAAUGGACUGCAGAUCCGCTT }\end{array}$ & & & \\
\hline si-C/EBP $\alpha$ & $\begin{array}{l}\text { F: ACGAGACGUCCAUCGACAUTT } \\
\text { R: AUGUCGAUGGACGUCUCGUTT }\end{array}$ & & & \\
\hline si-NC & $\begin{array}{l}\text { F: UUCUCCGAACGUGUCACGUTT } \\
\text { R: UUAACUCAUCGCUUCUUGCTT }\end{array}$ & & & \\
\hline
\end{tabular}

GCTAGC: The the bold and underlined represent restriction site. GGTC: the bold and underlined represent

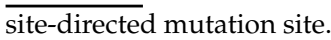

\subsection{Cell Culture, Transfection, and Dual-Luciferase Reporter Assay}

The 293T cells and Porcine alveolar macrophages (3D4/21) were purchased from BeNa Culture Collection (BNCC, Beijing, China). The cells were cultured in growth medium containing $90 \%$ DMEM (HyClone, New York, NY, USA), 10\% fetal bovine serum (Invitrogen, Carlsbad, CA, USA), and $1 \%$ antibiotics (100 IU/ml penicillin and $100 \mu \mathrm{g} / \mathrm{ml}$ streptomycin) at $37{ }^{\circ} \mathrm{C}$ and $5 \% \mathrm{CO}_{2}$. When the cells reached $70-80 \%$ confluence, cells were incubated in 24 -well plates. For transfection, cells were transfected using Lipofectamine ${ }^{\mathrm{TM}} 2000$ reagent (Invitrogen, Carlsbad, CA, USA). In order to determine the core promoter of HMOX1 gene, a series of promoter fragments $(-1878 /+115,-1617 /+115$, 
$-919 /+115,-387 /+115,-158 /+115)$ were amplified through $5^{\prime}$ unidirectional deletion specific primers containing Nhe I and Xho I restriction enzyme sites, respectively. The PCR products were cloned into pGL3-basic luciferase reporter vector (Progema, Madison, WI, USA) using T4 DNA Ligase (TaKaRa, Dalian, China). After enzyme digestion and sequencing identification, the recombinant plasmids were extracted using EndoFree Mini Plasmid Kit II (TIANGEN, Beijing, China), and named pGL3-1878/+115, pGL3-1617/+115, pGL3-919/+115, pGL3-387/+115, and pGL3-158/+115, respectively. In order to verify the promoter activity of different fragments, each recombinant plasmid (800 ng) was co-transfection with internal vector pRL-TK $(20 \mathrm{ng})$ using Lipofectamine ${ }^{\mathrm{TM}} 2000$ reagent according to the manufacturer's protocol. After $48 \mathrm{~h}$ post-transfection, the luciferase activity was detected using the Dual Luciferase Reporter Assay System (Promega, Madison, WI, USA), the pGL3-basic vector was considered as a negative control. Each group was performed three times.

\subsection{Site-Directed Mutagenesis}

The AliBaba2.1 and JASPAR online software were used to predict the transcription factor binding sites in core promoter region. In the present study, we mutated the potential transcription factor binding sites for WT1, Sp1, C/EBP $\alpha$, and c-Ets-1 with the corresponding primers (Table 1) using Fast Site-Directed Mutagenesis Kit (TIANGEN, Beijing, China) according to the instruction manual.

\subsection{RNA Interference}

The siRNAs used in this experiment were designed and synthesized by GenePharma Company (Shanghai, China). The si-NC was regarded as a negative control. The interference sequences were shown in Table 1. Porcine alveolar macrophages (3D4/21) were cultured in 24-well plates and siRNAs (50 nM) co-transfected with pGL3-387/-158 plasmid (500 ng) according to the method mentioned before. After $48 \mathrm{~h}$ post-transfection, the relative mRNA expression and luciferase activity were measured as described above.

\subsection{Statistical Analysis}

The IBM SPSS Statistics (version 21.0) were used to analyze the relative mRNA expression levels of HMOX1 gene in different tissues of Hezuo Tibetan pig, and the Duncan method was used to compare multiple groups. Independent sample $t$-test was used to analyze the relative luciferase activity among different promoter fragments. GraphPad Prism 8.0 software (Huntington, West Virginia, USA) was used for drawing. All values in this study were expressed as the mean \pm standard deviation (SD). * indicates $p<0.05,{ }^{* *}$ indicates $p<0.01, \mathrm{n}=3$.

\section{Results}

\subsection{Tissue Expression Analysis of $m R N A$}

Total RNA was extracted from fourteen tissues (heart, liver, spleen, lung, kidney, stomach, duodenum, jejunum, ileum, cecum, colon, rectum, psoas muscle, longissimus dorsi), qRT-PCR was used to analyzed the mRNA expression profiles of different tissues. Compared with the expression of HMOX1 in the duodenum, the relative expression level of adults Hezuo Tibetan pig was shown in Figure 1. The HMOX1 gene expression in the spleen was highest $(p<0.01)$ compared to other tissues. In addition, the liver, lung, kidney, and heart tissues also had the higher expression levels. 


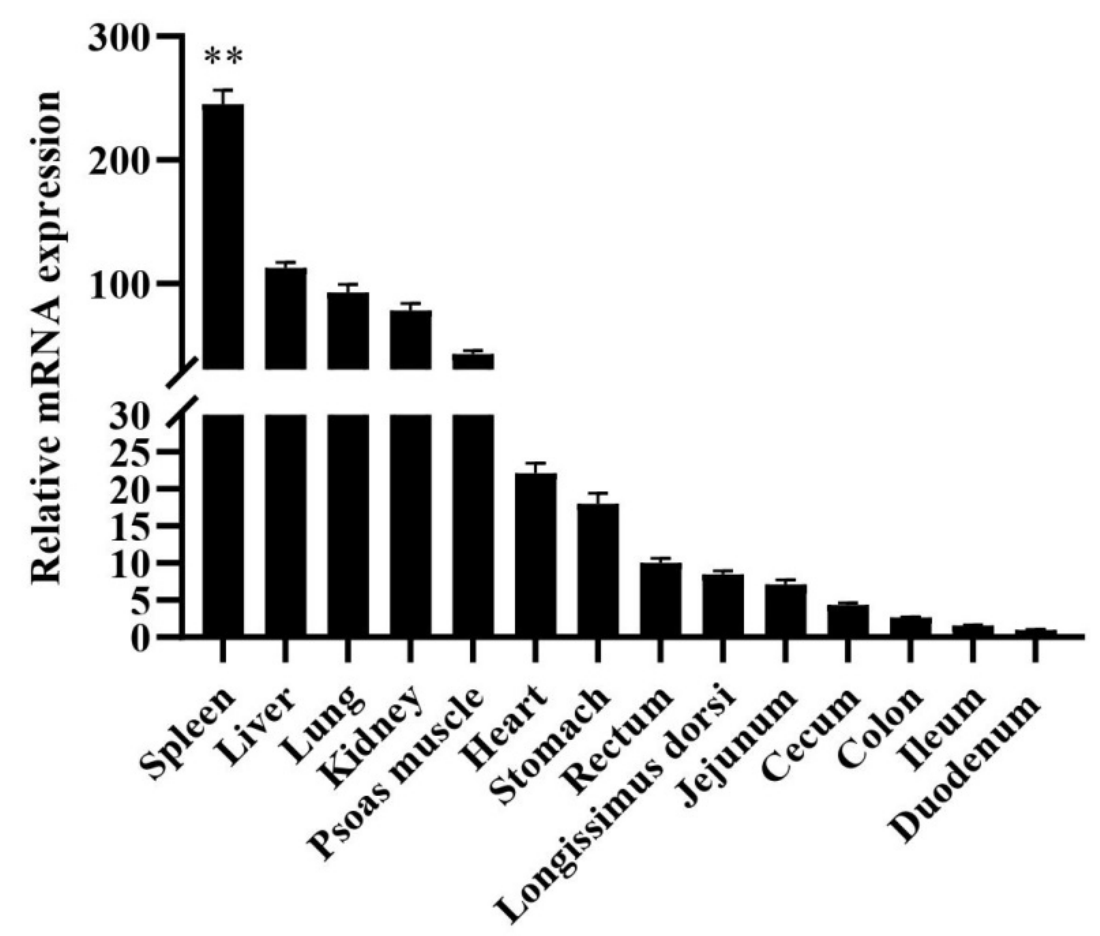

Figure 1. Relative expression patterns of Hezuo Tibetan pig HMOX1 gene in different tissues. The result was normalized with $\beta$-actin gene and relative to gene expression in the duodenum group. ${ }^{* *}$ indicates $p<0.01$.

\subsection{Promoter Region Cloning and Bioinformatics Analysis}

Based on the pig HMOX1 gene sequence published by GenBank database (NM_001004027.1), a 2125 bp 5'-flanking sequence spanning nucleotides from -1911 to +214 bp was amplified (Figure 2A). We used NCBI-BLAST program to perform a sequence alignment analysis between the cloned Hezuo Tibetan pig promoter region sequence and $2125 \mathrm{bp}$ sequence upstream of the pig HMOX1 gene in NCBI, and found that the sequence similarity was $96.63 \%$. In addition, we summarized the gene structure of HMOX1 and found that it contains five exons in genome, and the length is about $9 \mathrm{~kb}$. The mRNA (NM_001004027.1) transcript length is $1552 \mathrm{bp}$. In addition, an open reading frame (ORF) of $867 \mathrm{bp}$, which encoded 288 amino acids (aa) with one conserved domain, the Heme_oxygenase domain (in aa 11 to 216) was identified (Figure 2B). The results are shown in. The transcription start site (TSS) was predicted through Neural Network Promoter Prediction and the adenine residue (A) proximal to $5^{\prime}$ untranslated regions was verified and designated as +1 (Figure 2D). The CpG island was predicted by MethPrimer online software and found that two CpG islands located in 197 bp (-1516 -1320) and $225 \mathrm{bp}(-164 \sim 61)$ at promoter region (Figure $2 \mathrm{C})$. 
A

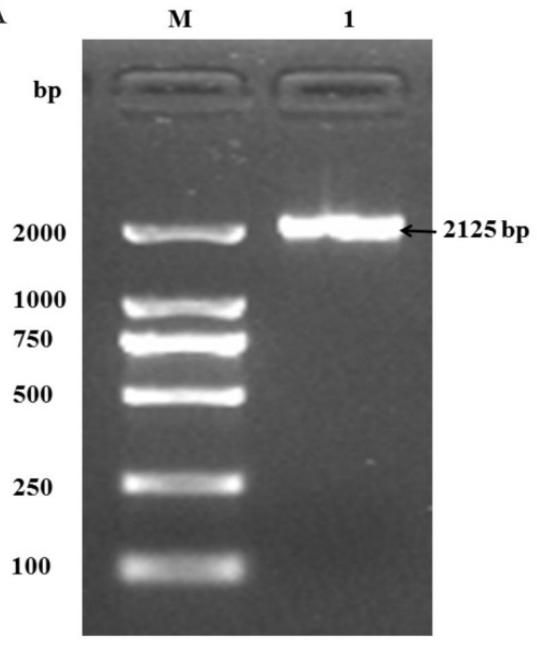

B

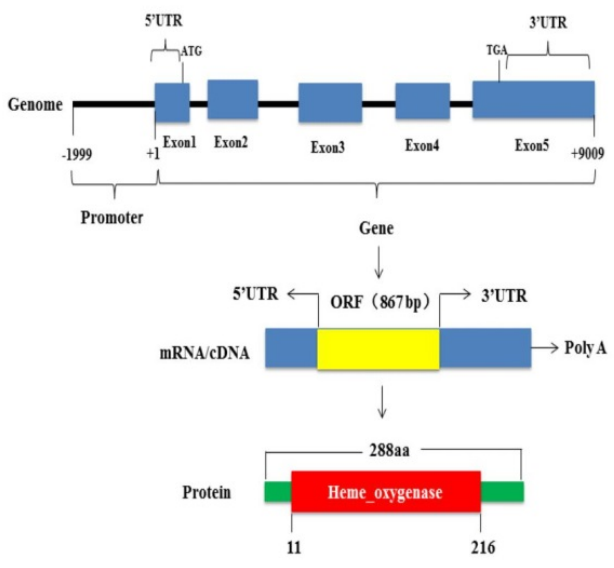

D
-1911 gcctcgtcettctaaagtccetctaaggatgetcagcaacccccaagtctctgga HMOX1-P-F PGL-1878/+115-F
1856 tggatttggtgagacttgggtaagtgatcctggaagaggatggatcacgggctccg 1800 acettrgato 1745 gctogect 1745 gctcaaggace 1688 ctgcggtccccagtggagactccatgcctgacgggecgtcctcaagcetgagtgc 1633 acattcettcagaagtgggcactcgataccttggttccaaacaacagecttatcat
1577 aagcctaagtcacetttttgattaatcgagaatccagaatttcagcattggaaaggg 1519 getttaagaatcatccagtetgggagttccegtcgeggetcagtggttaacgaatcc 1462 gactaggaaccatgaggttgegggttcgatccetggecttgetcagtgggttaagg -1404 atccggcgttgetgtgagctgtggtgtaggttgcagacgeggetcggatccogtgtt -1349 getgtggetctggegtaggccggtggetacagctccaattagacccetagcetggg 1293 aacctccaagtgecgcaggtgtggcccaagaaaatggcaaaaaaacaaaaaa -1239 caaaacaaaacaaaagaatcatccagtctgggagttgecatcatggetcggcagtt 1183 aacaaacccgactagtatccetgaggatacaggttccatccetggcctcgctcagt 1126 gattaaggatccagtattgccatgaactotgotgtaggtcaaagatgtggetcag 1068 ctroto 068 cteatceca 1012 gcctgggacettccatatgccaggggtgcggetctaaaaagacaaaaaaaaaaa
-957 aaaaaaaaaaatccggectgttcgtttgtcatttaggetccctagtagtaaccttt -957 aaaaaaaaaaaatccggectgttcgtttgtcatttaggctccctagtagtaacc
-895 ctcctagtcetgagtggtcagectcacggagaattaattcgatacttgatcagaggg $\mathbf{8 3 8}$ ccagctctgctcaggeccagagcaggcaccgaggatgagctgtatcagatctaat -783 gagctccggaagagcatcctatgcagggaagetggggagtcgtettggataacca -728 gcatctetgtccagetggggacaagagggectggaggaggeaggcagggacet -675 ggactcctcetgggtgtcaggtcccaatgtcetgetttatgtgtgacettgggcaagc -617 ccetgcactcteccagagectcagtttccetgectgtaaaatggtactgetctaccc $\mathbf{5 5 9}$ cacagttgttgggatggacettgaacgcagtacagtctctagcacatagtaggtgct 502 caagtaaaaagaagaaaaagaaaccctaaaaggacattaaagatagtocgagco 448 cacgggetgecagetgagggtccaggaaggagggtcc cagaacgggggag
pGL-387/+115-F
398 acgactgcaggCAGGGTTTGGGGTGC
TGCAGAAGTCCCG -361 AGGTCGCCCAGCCTCCCGTCAGAGAAGCGCTGC 326 CTCCCAGCTCTGTGGCACCATTCAGATCCGTGGGG
291 GTGCTCAAGTCCCATCGCTGGGTGGGAGGCTCTGG -256 GAGGGACAAAATCACACTACTTACTGCTCAGATGC -221 CTAAAGTATCTTTTGCTITGCTTTTAG TGTCCTGTTT -184 TAAACAGCTCTGTTTTCCAAGGGTCA atgaccgetcetcc pGL-158/+115-F
143 tccaccccocaggecaggggcgg
-90 acgtcggeccacaaagtgggagatcagetgtegggeggeggecacgtgaccc
$\longrightarrow$ TSS $(+1)$
-38 geccegggaataaatggacegegcggccagegctcggca +16 cetcetcgaccecgtegegagetgtcggageagecagececggagecetccecg +70 agcgecgegecgecgcagcATGgagcactcacagcccaacaggcaagcgt PGL+115-R
+119 ggggeagecgetgecetcecgecgecgagetcecgaggetgagecgggaagca +172 ggaagcgacetcgetgagcggecagtcacttgggetttggcg

C

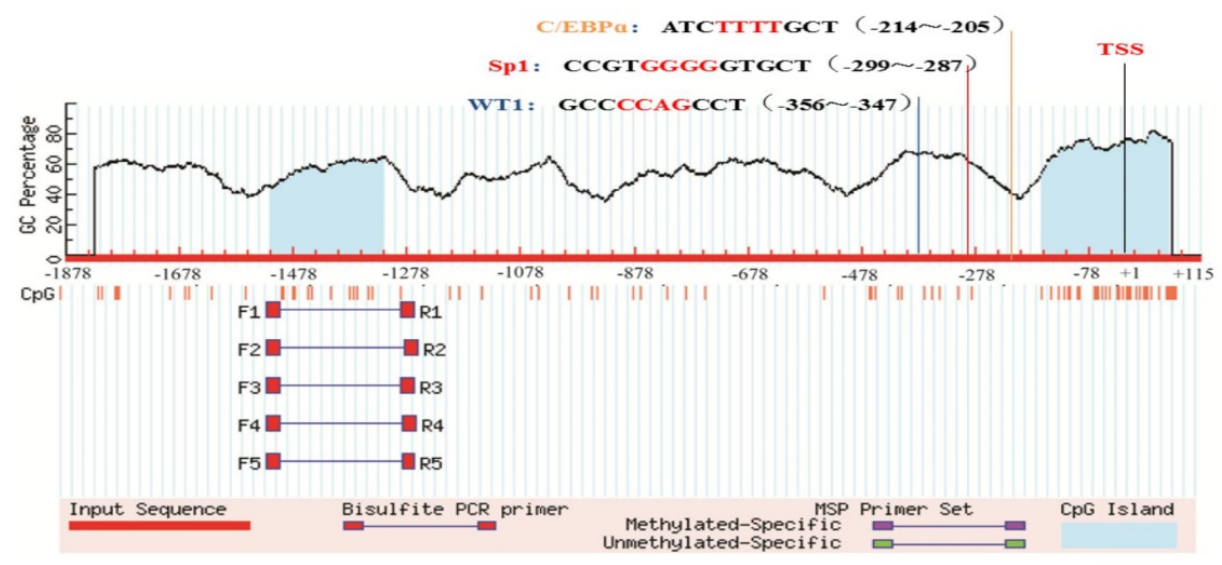

Figure 2. Promoter region cloning and bioinformatics analysis. (A) PCR amplification product of HMOX1 gene promoter region. M, DL2000 DNA marker; 1, PCR product. (B) Genomic structure of HMOX1 gene. (C) The predict results of CPG island in HMOX1 gene. (D) The promoter sequence information of HMOX1 gene. The box represents the transcription factor binding sites, and the $4 \mathrm{bp}$ core binding sites are shown in red. The underline represents the amplification primer and the arrow represents the transcription start site (TSS). 


\subsection{Promoter Activity Analysis and Core Promoter Region Identification}

Through enzyme digestion and sequencing, we successfully constructed five recombinant vectors as shown in Figure 3B. Then we measured luciferase activity to find the core promoter region of HMOX1 gene. The results indicated that pGL3-387/+115 had the highest transcription activity compared to other regions and significantly increase compared to the pGL3-158/+115 recombinant plasmid $(p<0.01)$ (Figure 3A). In order to identify the minimum core promoter region, we constructed the pGL3-387/-158 recombinant vector by subcloning, and the luciferase activity was shown that the pGL3-387/-158 significantly increase compared to pGL-158/+115 $(p<0.01)$. This suggested that $-387 /-158$ as the core promoter region of HMOX1 gene (Figure 3C). We further analyzed transcriptional regulatory elements in this region using AliBaba2.1 and JASPAR. As a result, four essential transcription factors-WT1, Sp1, $\mathrm{C} / \mathrm{EBP} \alpha$, and c-Ets-1-were predicted in the core promoter region (Figure $4 \mathrm{~A}$ ). In addition, multiple alignments of core promoter region sequences between six species (pig, human, mouse, cattle, sheep, and horse). The results showed that the $\mathrm{WT} 1, \operatorname{Sp} 1, \mathrm{C} / \mathrm{EBP} \alpha$, and c-Ets-1 regulatory elements were conserved in livestock (Figure 4B).

A

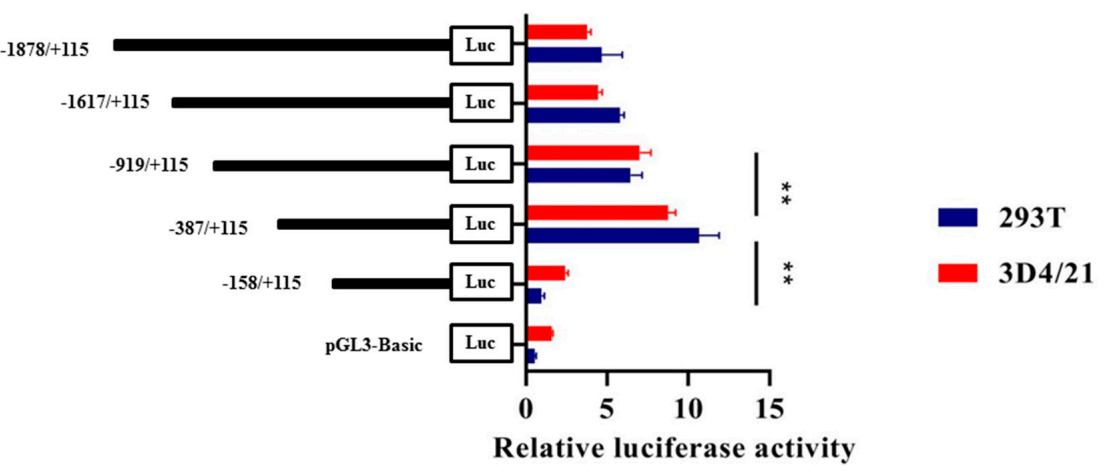

B

$\mathrm{C}$
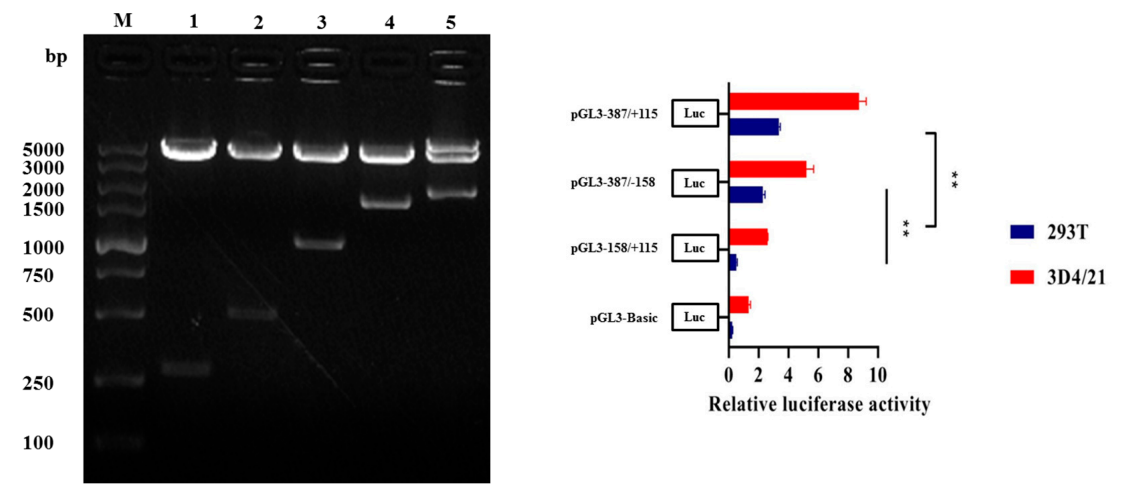

Figure 3. Construction of different deletion vectors of $H M O X 1$ gene promoter region and luciferase activity analysis. (A) Luciferase activity analysis of promoter with different deletion vectors (pGL3-1878/+115, pGL3-1617/+115, pGL3-919/+115, pGL3-387/+115, pGL3-158/+115), pGL3-Basic as a negative control. (B) Double enzyme digestion identification of different deletion vectors. $M$, DL5000 DNA marker, lanes 1-5 are different deletion fragments. (C) Analysis of luciferase activity in the core promoter region. All ${ }^{* *}$ represents $p<0.01$. 
A
$-387$ WT1
CAGGGTTTGGGGTGCAGAAGTCCCTGAGGTCGCCCCAGCCTCCCGCTCAGAGAAGCGCTGCC TCCCAGCTCTGTGGCACCATTCAGATCCGTGGGGGTGCTCAAGTCCCATCGCTGGGTGGGAGG CTCTGGGAGGGACAAAATCACACTACTTACTGCTCAGATTCCTAAAGTATCTTTTGCTITGTTTT TAGTGTCCTGTTTTAAACAGCTCTGTTTTCCAAGGGTCATATGACCGCTCCTCCTCCACCCCCGC AGGCCAGGGGCGGGTGGGGCGCGGGCCGCCGTGGGTGTTGCAACGTCGGGCCACAAAGTGG GAGATCGGCTGTCGGGCGGCGGCCACGTGACCCGCCCCGGGAATAAATGGACCGCGCGGCCA GCGCTCGGCACCGTCGGCCTCCCGCCTCCTCGACCCCGTCGCGAGCTGTCGGAGCAGCCAGCC TSS $(+1)$

B
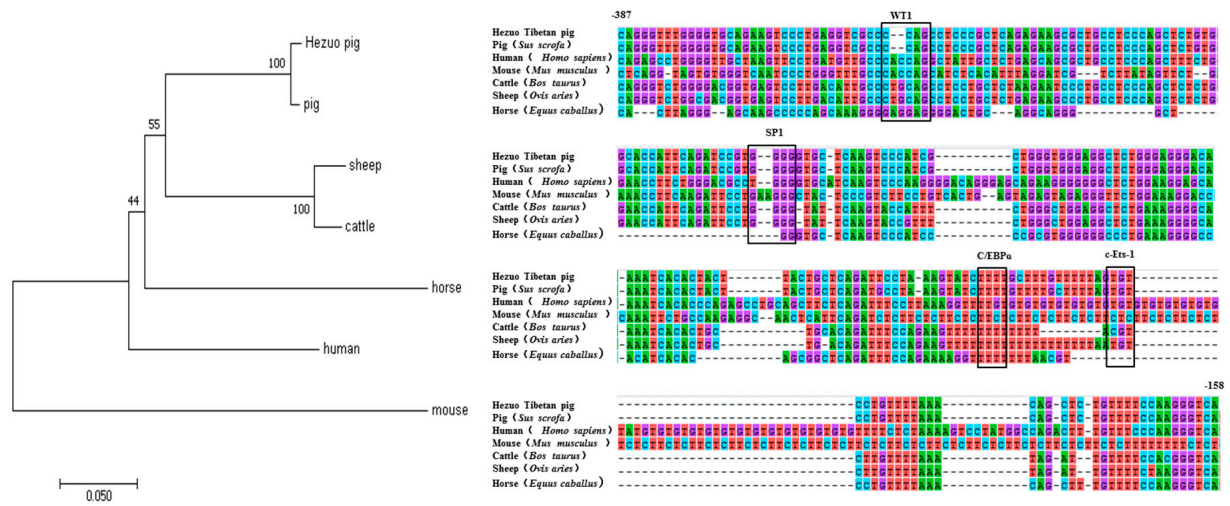

Figure 4. Transcription factor prediction and multi-species homology analysis in the core promoter region. (A) Transcription factor prediction of core promoter region. Four essential transcription factors WT1, Sp1, C/EBP $\alpha$, and c-Ets-1 were predicted in -387/-158, the location of the 4 bp core binding is indicated in red. (B) Sequence alignment and phylogenetic construction of core promoter regions in six species. The box represents the $4 \mathrm{bp}$ core binding site.

\subsection{Roles of WT1, Sp1, C/EBP $\alpha$, and c-Ets-1 in Transcriptional Regulation of HMOX1 Gene}

In order to explore the role of WT1, Sp1, C/EBP $\alpha$, and c-Ets-1 in the regulation transcription of HMOX1 gene, four recombinant plasmids with 4 bp point mutations in the WT1, Sp1, C/EBP $\alpha$, and c-Ets-1 binding sites in pGL-387/-158 were constructed. Then, the four mutant vectors were transfected into $293 \mathrm{~T}$ and 3D4/21 cells to detect the luciferase activity, respectively. The results showed that the luciferase activity of the mutated WT1, Sp1, and C/EBP $\alpha$ were significantly decreased $(p<0.01)$, while the luciferase activity of mutated c-Ets-1 had no significant changes (Figure 5A). To further validate the roles of $\mathrm{WT} 1, \mathrm{Sp} 1$, and $\mathrm{C} / \mathrm{EBP} \alpha$ binding sites in the core promoter region of the HMOX1 gene, the selected transcription factors were silenced through siRNAs. First, the interference efficiency of the siRNAs (si-WT1, si-Sp1, and si-C/EBP $\alpha$ ) were detected through negative control siRNA after transfection $24 \mathrm{~h}$. The results showed that these siRNAs significantly reduced $(p<0.01)$ the mRNA expression levels of the WT1, Sp1, and C/EBP $\alpha$ as compared to the negative control (Figure 5B). In addition, the relative mRNA expression level of HMOX1 gene had significantly decrease $(p<0.05$ and $p<0.01$ ) by WT1, Sp1, and C/EBP $\alpha$ inhibition, respectively (Figure 5C). Further co-transfection of si-WT1, si-Sp1, or si-C/EBP $\alpha$ with pGL-387/-158 also reduced luciferase activity (Figure 5D). In this context, we see that $\mathrm{WT} 1, \mathrm{Sp} 1$, and $\mathrm{C} / \mathrm{EBP} \alpha$ can promote the transcriptional activity of promoter and increase the expression of HMOX1 gene. These three transcription factors may be bind to the core promoter region of HMOX1 gene and play a role in activating HMOX1 gene transcription. 


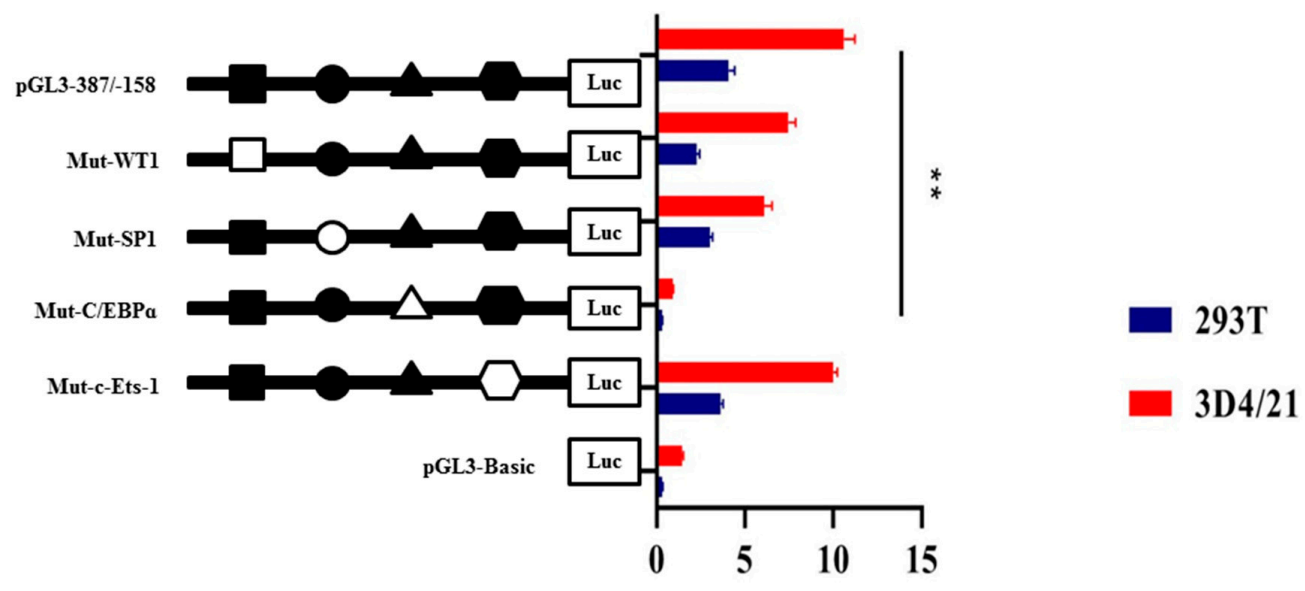

Relative luciferase activity

B

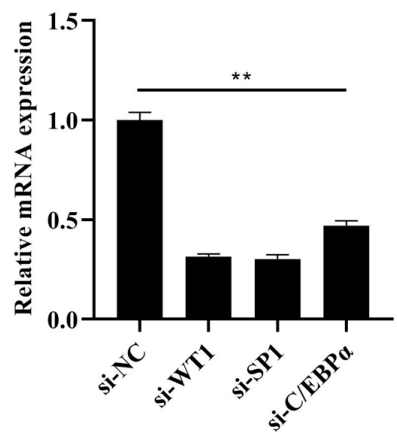

C

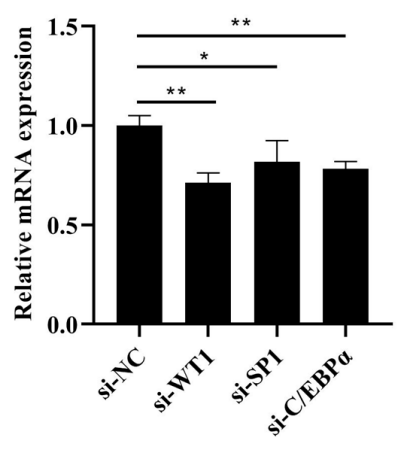

$\mathrm{D}$

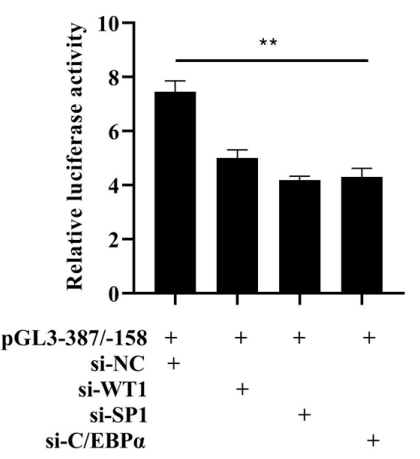

Figure 5. Role of $\mathrm{WT} 1, \mathrm{Sp} 1$, and $\mathrm{C} / \mathrm{EBP} \alpha$ in the transcription regulation of HMOX1 gene. (A) Luciferase activity analysis with site-directed mutagenesis of $\mathrm{WT} 1, \operatorname{Sp} 1, \mathrm{C} / \mathrm{EBP} \alpha$, and c-Ets- 1 sites. Solid and hollow represent wild-type and mutant-type, respectively. (B) Interference efficiency of WT1, Sp1, and $\mathrm{C} / \mathrm{EBP} \alpha$. (C) The mRNA expression level of HMOX1 gene by inhibition with si-WT1, si-Sp1, and si-C/EBP $\alpha$. (D) Luciferase activity after co- transfection of si-WT1, si-Sp1, and si-C/EBP $\alpha$ with pGL3-387/-158. ( ${ }^{*}$ indicates $p<0.05,{ }^{* *}$ indicates $p<0.01$ ).

\section{Discussion}

Heme oxygenase (HO) family has three important members, including inducible HMOX1 and constitutive HMOX2 and HMOX3 [25,26]. The HMOX1 gene, also known as heat-shock protein 32 (HSP32), plays an important role in protecting the body from a variety of stimuli and pathological conditions [27-29]. Studies have reported that vascular endothelial growth factor (VEGF) can regulate the expression of HMOX1 gene and play an important regulatory role in angiogenesis [30,31]. Wang et al. [32] found that HMOX1 has a protective effect in fish hypoxic cells. In addition, Gou et al. [33] reported that increasing hemoglobin content is a key molecular mechanism of hypoxia adaptation in Tibetan chicken embryos. These studies suggest that the HO family genes may play an important protective role in the body's anti-inflammatory, antioxidant stress, and hypoxia injury activities.

In this study, the expression profiles of HMOX1 gene in Hezuo Tibetan pigs were analyzed in 14 tissues and found that the expression level of HMOX1 gene in spleen tissue was the highest, followed by liver, lung, and kidney. This results are consistent with the previous findings of Kovtunovych 
et al. [34] on mice and Park et al. [35] on transgenic pigs. At present, bioinformatics analysis and construction of luciferase reporter gene vectors are common methods to study promoter activity and core regulatory regions [36]. In this work, we successfully constructed recombinant vectors with different deletion lengths in the HMOX1 gene promoter region and detected luciferase activity after transfection of $293 \mathrm{~T}$ cells and 3D4/21 cells. It was found that the HMOX1 gene promoter region $-387 /-158$ had the highest activity, indicating that there were important positive regulatory transcription elements in this region. Subsequently, bioinformatics predicted that the promoter region $-387 /-158$ of HMOX1 gene contains crucial transcription factor binding sites such as WT1, Sp1, C/EBP $\alpha$, and c-Ets-1. Further combined with site-directed mutagenesis and RNA interference experiments, we have preliminarily confirmed that WT1, Sp1, and C/EBP $\alpha$ can activate the promoter activity of $H M O X 1$ gene. Transcription factors can bind to specific DNA sequences in the gene promoter region to control the transcription and expression of genes, thereby regulating various physiological activities of the body [36]. The siRNAs can specifically inhibit or degrade the expression of homologous mRNA, thereby mediating gene post-transcriptional silencing [37]. In this study, si-WT1, si-Sp1, and si-C/EBP $\alpha$ were designed and synthesized. After transfected into 3D4/21 cells, it was found that si-WT1, si-Sp1, and si-C/EBP $\alpha$ could effectively inhibit the expression of HMOX1 mRNA level, and can reduce the HMOX1 gene promoter activity. The previous study found that WT1 transcription factor (WT1) can play a role in heart and blood vessel formation [38]. It was also regarded as a key element in acute myeloid leukemia [39], and WT1 overexpression was an independent positive prognostic factor in adult B-cell acute lymphoblastic leukemia patients [40]. The transcription factor Sp1 (Sp1) can regulate the expression of multiple genes [41], which can play a role in the body's antioxidant stress [42]. Under hypoxic and ischemic conditions, regulating the expression of Sp1 can regulate the activation mechanism of coagulation in rats with hemorrhagic shock [43]. Sp1 can promote TGF- $\beta 1$ expression and activate the SMAD2 pathway, the SP1/TGF- $\beta 1 / S M A D 2$ pathway may enhance angiogenic processes in preosteoblasts [44]. Deshane et al. [45] showed that Sp1 also regulated the expression of HMOX1 gene in human kidney cells. CCAAT/enhancer binding protein $\alpha(\mathrm{C} / \mathrm{EBP} \alpha)$ can play a role in cell proliferation, apoptosis, inflammation, and other responses. According to previous study, the $\mathrm{C} / \mathrm{EBP} \alpha$ can play a role in the development of lipogenesis [46] and acute myeloid leukemia [47]. Liu et al. [48] found that $\mathrm{C} / \mathrm{EBP} \alpha$ was a key target gene of DNA methyltransferase 1 (Dnmt1) downstream, which can play a crucial role in maintain hematopoietic stem and progenitor cells in zebrafish. It has also been reported that $\mathrm{C} / \mathrm{EBP} \alpha$ can increase the expression of HMOX1 gene under the induction of peptidoglycan [49]. Taken together, the transcription factors WT1, Sp1, and C/EBP $\alpha$ can regulate the expression of multiple genes and participate in a variety of biological processes related to hematopoietic function. Therefore, we speculate that transcription factors WT1, Sp1, and C/EBP $\alpha$ may be significant factors in regulating $H M O X 1$ gene, this research may provide a positive reference for further studying the transcriptional regulation mechanism of HMOX1 gene.

\section{Conclusions}

In conclusion, in the present study, we analyzed $H M O X 1$ gene expression profiles and gene structure. We also cloned 5' promoter region and predicted the transcription initiation site of Hezuo Tibetan pig HMOX1 gene. In addition, we discovered that the core promoter region and three transcription factors $\mathrm{WT} 1, \mathrm{Sp} 1$, and $\mathrm{C} / \mathrm{EBP} \alpha$ are likely to play an important role in the expression of HMOX1 gene in Hezuo Tibetan pig. Our results will provide a basic information for further research the transcriptional regulation mechanism of HMOX1 gene.

Author Contributions: W.W. and Z.Y. conceived this study; W.W. and Q.Y. designed experiments; K.X. contributed to vectors construction; P.W., X.G., B.Z., and X.H. contributed to samples collection; W.W. and R.L. contributed to cell culture; W.W. wrote the paper; W.W., Q.Y., and S.G. checked and revised the paper. All authors have read and agreed to the published version of the manuscript.

Funding: This research was funded by special talents fund of Gansu Agricultural University (2017RCZX-15). 
Acknowledgments: We acknowledge and thank the GENEWIZ (Suzhou, China) and GenePharma (Shanghai, China) biotechnology co. ltd. for its technical support in this experiment.

Conflicts of Interest: The authors declare no conflicts of interest.

\section{References}

1. Gan, M.L.; Shen, L.Y.; Fan, Y.; Guo, Z.X.; Liu, B.; Chen, L.; Tang, G.Q.; Jiang, Y.Z.; Li, X.W.; Zhang, S.H.; et al. High altitude adaptability and meat quality in Tibetan pigs: A reference for local pork processing and genetic improvement. Animals 2019, 9, 1080. [CrossRef]

2. Zhang, B.; Qiangba, Y.Z.; Shang, P.; Wang, Z.X.; Ma, J.; Wang, L.Y.; Zhang, H. A comprehensive microRNA expression profile related to hypoxia adaptation in the Tibetan pig. PLoS ONE 2015, 10, e0143260. [CrossRef] [PubMed]

3. Ma, Y.F.; Han, X.M.; Huang, C.P.; Zhong, L.; Adeola, A.C.; Irwin, D.M.; Xie, H.B.; Zhang, Y.P. Population genomics analysis revealed origin and high-altitude adaptation of Tibetan pigs. Sci. Rep. 2019, 9, 11463. [CrossRef] [PubMed]

4. $\quad$ Li, M.Z.; Tian, S.L.; Jin, L.; Zhou, G.Y.; Li, Y.; Zhang, Y.; Wang, T.; Yeung, C.K.; Chen, L.; Ma, J.D.; et al. Genomic analyses identify distinct patterns of selection in domesticated pigs and Tibetan wild boars. Nat. Genet. 2013, 45, 1431-1438. [CrossRef] [PubMed]

5. Ai, H.S.; Yang, B.; Li, J.; Xie, X.H.; Chen, H.; Ren, J. Population history and genomic signatures for high-altitude adaptation in Tibetan pigs. BMC Genom. 2014, 15, 834. [CrossRef] [PubMed]

6. Kong, X.Y.; Dong, X.X.; Yang, S.L.; Qian, J.H.; Yang, J.F.; Jiang, Q.; Li, X.R.; Wang, B.; Yan, D.W.; Lu, S.X.; et al. Natural selection on TMPRSS6 associated with the blunted erythropoiesis and improved blood viscosity in Tibetan pigs. Comp. Biochem. Physiol. B Biochem. Mol. Biol. 2019, 233, 11-22. [CrossRef] [PubMed]

7. Otterbein, L.E.; Soares, M.P.; Yamashita, K.; Bach, F.H. Heme oxygenase-1: Unleashing the protective properties of heme. Trends Immunol. 2003, 24, 449-455. [CrossRef]

8. Kishimoto, Y.; Kondo, K.; Momiyama, Y. The Protective Role of Heme Oxygenase-1 in Atherosclerotic Diseases. Int. J. Mol. Sci. 2019, 20, 3628. [CrossRef]

9. Lin, H.H.; Chen, Y.H.; Chang, P.F.; Lee, Y.T.; Yet, S.F.; Chau, L.Y. Heme oxygenase-1 promotes neovascularization in ischemic heart by coinduction of VEGF and SDF-1. J. Mol. Cell. Cardiol. 2008, 45, 44-55. [CrossRef]

10. Singh, S.P.; Greenberg, M.; Glick, Y.; Bellner, L.; Favero, G.; Rezzani, R.; Rodella, L.F.; Agostinucci, K.; Shapiro, J.I.; Abraham, N.G. Adipocyte specific HO-1 gene therapy is effective in antioxidant treatment of insulin resistance and vascular function in an obese mice model. Antioxidants 2020, 9, 40. [CrossRef]

11. Inguaggiato, P.; Gonzalez-Michaca, L.; Croatt, A.J.; Haggard, J.J.; Alam, J.; Nath, K.A. Cellular overexpression of heme oxygenase-1 up-regulates p21 and confers resistance to apoptosis. Kidney Int. 2001, 60, 2181-2191. [CrossRef] [PubMed]

12. Takao, M.; Okinaga, T.; Ariyoshi, W.; Iwanaga, K.; Nakamichi, I.; Yoshioka, I.; Tominaga, K.; Nishihara, T. Role of heme oxygenase-1 in inflammatory response induced by mechanical stretch in synovial cells. Inflamm. Res. 2011, 60, 861-867. [CrossRef] [PubMed]

13. Yachie, A.; Niida, Y.; Wada, T.; Igarashi, N.; Kaneda, H.; Toma, T.; Ohta, K.; Kasahara, Y.; Koizumi, S. Oxidative stress causes enhanced endothelial cell injury in human heme oxygenase-1 deficiency. J. Clin. Investig. 1999, 103, 129-135. [CrossRef] [PubMed]

14. Brouard, S.; Otterbein, L.E.; Anrather, J.; Tobiasch, E.; Bach, F.H.; Choi, A.M.K.; Soares, M.P. Carbon monoxide generated by heme oxygenase 1 suppresses endothelial cell apoptosis. J. Exp. Med. 2000, 192, 1015-1026. [CrossRef]

15. Kawamura, K.; Ishikawa, K.; Wada, Y.; Kimura, S.; Matsumoto, H.; Kohro, T.; Itabe, H.; Kodama, T.; Maruyama, Y. Bilirubin from heme oxygenase-1 attenuates vascular endothelial activation and dysfunction. Arter. Thromb Vasc Biol. 2005, 25, 155-160. [CrossRef]

16. Clark, J.E.; Foresti, R.; Sarathchandra, P.; Kaur, H.; Green, C.J.; Motterlini, R. Heme oxygenase-1-derived bilirubin ameliorates postischemic myocardial dysfunction. Am. J. Physiol. Heart Circ. Physiol. 2000, 278, H643-H651. [CrossRef] 
17. Fujiwara, A.; Hatayama, N.; Matsuura, N.; Yokota, N.; Fukushige, K.; Yakura, T.; Tarumi, S.; Go, T.; Hirai, S.; Naito, M.; et al. High-pressure carbon monoxide and oxygen mixture is effective for lung preservation. Int. J. Mol. Sci. 2019, 20, 2719. [CrossRef]

18. Rashid, I.; Baisvar, V.S.; Singh, M.; Kumar, R.; Srivastava, P.; Kushwaha, B.; Pathak, A.K. Isolation and characterization of hypoxia inducible heme oxygenase 1 (HMOX1) gene in Labeo rohita. Genomics 2020, 112, 2327-2333. [CrossRef]

19. Taylor, J.L.; Carraway, M.S.; Piantadosi, C.A. Lung-specific induction of heme oxygenase-1 and hyperoxic lung injury. Am. J. Physiol. 1998, 274, L582-L590. [CrossRef]

20. Mitchell, P.J.; Tjian, R. Transcriptional regulation in mammalian cells by sequence-specific DNA binding proteins. Science 1989, 245, 371-378. [CrossRef]

21. Livak, K.J.; Schmittgen, T.D. Analysis of relative gene expression data using real-time quantitative PCR and the $2^{-\triangle \Delta \mathrm{Ct}}$ method. Methods 2000, 25, 402-408. [CrossRef] [PubMed]

22. Wingender, E.; Dietze, P.; Karas, H.; Knüppel, R. TRANSFAC: A database on transcription factors and their DNA binding sites. Nucleic Acids Res. 1996, 24, 238-241. [CrossRef] [PubMed]

23. Fornes, O.; Castro-Mondragon, J.A.; Khan, A.; van der Lee, R.; Zhang, X.; Richmond, P.A.; Modi, B.P.; Correard, S.; Gheorghe, M.; Baranašić, D.; et al. JASPAR 2020: Update of the open-access database of transcription factor binding profiles. Nucleic Acids Res. 2019, 48, D87-D92. [CrossRef] [PubMed]

24. Li, L.C.; Dahiya, R. MethPrimer: Designing primers for methylation PCRs. Bioinformatics 2002, 11, 1427-1431. [CrossRef]

25. Mccoubrey, W.K.; Ewing, J.F.; Maines, M.D. Human heme oxygenase-2: Characterization and expression of a full-length cDNA and evidence suggesting that the two HO-2 transcripts may differ by choice of polyadenylation signal. Arch. Biochem. Biophys. 1992, 295, 13-20. [CrossRef]

26. Mccoubrey, W.K.; Huang, T.J.; Maines, M.D. Isolation and Characterization of a cDNA from the Rat Brain that Encodes Hemoprotein Heme Oxygenase-3. Eur. J. Biochem. 1997, 247, 725-732. [CrossRef]

27. Li, L.; Li, C.M.; Wu, J.; Huang, S.; Wang, G.L. Heat shock protein 32/heme oxygenase-1 protects mouse Sertoli cells from hyperthermia-induced apoptosis by CO activation of sGC signalling pathways. Cell Biol. Int. 2014, 38, 64-71. [CrossRef]

28. Stuhlmeier, K.M. Activation and regulation of Hsp32 and Hsp70. Eur. J. Biochem. 2000, 267, 1161-1167. [CrossRef]

29. Taylor, L.; Hillman, A.R.; Midgley, A.W.; Peart, D.J.; Chrismas, B.; McNaughton, L.R. Hypoxia-mediated prior induction of monocyte-expressed HSP72 and HSP32 provides protection to the disturbances to redox balance associated with human sub-maximal aerobic exercise. Amino Acids 2012, 43, 1933-1944. [CrossRef]

30. Bussolati, B.; Mason, J.C. Dual role of VEGF-induced heme-oxygenase-1 in angiogenesis. Antioxid. Redox Signal. 2006, 8, 1153-1163. [CrossRef] [PubMed]

31. Dulak, J.; Loboda, A.; Zagórska, A.; Józkowicz, A. Complex role of heme oxygenase-1 in angiogenesis. Antioxid. Redox Signal. 2004, 6, 858-866. [CrossRef] [PubMed]

32. Wang, D.; Zhong, X.P.; Qiao, Z.X.; Gui, J.F. Inductive transcription and protective role of fish heme oxygenase-1 under hypoxic stress. J. Exp. Biol. 2008, 211, 2700-2706. [CrossRef]

33. Gou, X.; Li, N.; Lian, L.S.; Yan, D.W.; Zhang, H.; Wei, Z.H.; Wu, C.X. Hypoxic adaptations of hemoglobin in Tibetan chick embryo: High oxygen-affinity mutation and selective expression. Comp. Biochem. Physiol. B Biochem. Mol. Biol. 2007, 147, 147-155. [CrossRef] [PubMed]

34. Kovtunovych, G.; Eckhaus, M.A.; Ghosh, M.C.; Ollivierrewilson, H.; Rouault, T.A. Dysfunction of the heme recycling system in heme oxygenase 1-deficient mice: Effects on macrophage viability and tissue iron distribution. Blood 2010, 116, 6054-6062. [CrossRef] [PubMed]

35. Park, S.J.; Cho, B.; Koo, O.J.; Kim, H.; Kang, J.T.; Hurh, S.; Kim, S.J.; Yeom, H.J.; Moon, J.; Lee, E.M.; et al. Production and characterization of soluble human TNFRI-Fc and human HO-1 (HMOX1) transgenic pigs by using the F2A peptide. Transgenic Res. 2014, 23, 407-419. [CrossRef] [PubMed]

36. Alam, J. Functional analysis of the heme oxygenase-1 gene promoter. Curr. Protoc. Toxicol. 2000, 6. [CrossRef] [PubMed]

37. Elbashir, S.M.; Harborth, J.; Lendeckel, W.; Yalcin, A.; Weber, K.; Tuschl, T. Duplexes of 21-nucleotide RNAs mediate RNA interference in cultured mammalian cells. Nature 2001, 411, 494-498. [CrossRef]

38. Scholz, H.; Wagner, K.D.; Wagner, N. Role of the Wilms' tumour transcription factor, Wt1, in blood vessel formation. Pflug. Arch. 2009, 458, 315-323. [CrossRef] 
39. Panuzzo, C.; Signorino, E.; Calabrese, C.; Ali, M.S.; Petiti, J.; Bracco, E.; Cilloni, D. Landscape of Tumor Suppressor Mutations in Acute Myeloid Leukemia. J. Clin. Med. 2020, 9, 802. [CrossRef]

40. Wang, S.J.; Wang, C.; Li, T.; Wang, W.Q.; Hao, Q.Q.; Xie, X.S.; Wang, D.M.; Jiang, Z.X.; Liu, Y.F. WT1 overexpression predicted good outcomes in adult B-cell acute lymphoblastic leukemia patients receiving chemotherapy. Hematology 2020, 25, 118-124. [CrossRef]

41. Bouwman, P.; Philipsen, S. Regulation of the activity of Sp1-related transcription factors. Mol. Cell. Endocrinol. 2002, 195, 27-38. [CrossRef]

42. Ryu, H.; Lee, J.; Zaman, K.; Kubilis, J.; Ferrante, R.J.; Ross, B.D.; Neve, R.; Ratan, R.R. Sp1 and Sp3 are oxidative stress-inducible, antideath transcription factors in cortical neurons. J. Neurosci. 2003, 23, 3597-3606. [CrossRef] [PubMed]

43. Xu, J.H.; Lu, S.J.; Wu, P.; Kong, L.C.; Ning, C.; Li, H.Y. Molecular mechanism whereby paraoxonase-2 regulates coagulation activation through endothelial tissue factor in rat haemorrhagic shock model. Int. Wound J. 2020, 1-7. [CrossRef] [PubMed]

44. Ding, A.; Bian, Y.Y.; Zhang, Z.H. SP1/TGF- $\beta 1 / S M A D 2$ pathway is involved in angiogenesis during osteogenesis. Mol. Med. Rep. 2020, 21, 1581-1589. [CrossRef] [PubMed]

45. Deshane, J.; Kim, J.; Bolisetty, S.; Hock, T.D.; Hill-Kapturczak, N.; Agarwal, A. Sp1 regulates chromatin looping between an intronic enhancer and distal promoter of the human heme oxygenase-1 gene in renal cells. J. Biol. Chem. 2010, 285, 16476-16486. [CrossRef] [PubMed]

46. Wang, X.Y.; Khan, R.; Raza, S.H.A.; Li, A.N.; Zhang, Y.; Liang, C.C.; Yang, W.C.; Wu, S.; Zan, L. Molecular characterization of ABHD5 gene promoter in intramuscular preadipocytes of Qinchuan cattle: Roles of Evi1 and C/EBP $\alpha$. Gene 2019, 690, 38-47. [CrossRef]

47. Reckzeh, K.; Cammenga, J. Molecular mechanisms underlying deregulation of C/EBP $\alpha$ in acute myeloid leukemia. Int. J. Hematol. 2010, 91, 557-568. [CrossRef]

48. Liu, X.H.; Jia, X.E.; Yuan, H.; Ma, K.; Chen, Y.; Jin, Y.; Deng, M.; Pan, W.J.; Chen, S.J.; Chen, Z.; et al. DNA methyltransferase 1 functions through C/ebpa to maintain hematopoietic stem and progenitor cells in zebrafish. J. Hematol. Oncol. 2015, 8, 15. [CrossRef]

49. Hung, C.C.; Liu, X.L.; Kwon, M.Y.; Kang, Y.H.; Chung, S.W.; Perrella, M.A. Regulation of heme oxygenase-1 gene by peptidoglycan involves the interaction of Elk-1 and C/EBP $\alpha$ to increase expression. Am. J. Physiol. Lung Cell Mol. Physiol. 2010, 298, 870-879. [CrossRef] 